Research Article

\title{
Wolbachia in guilds of Anastrepha fruit flies (Tephritidae) and parasitoid wasps (Braconidae)
}

\author{
Rodrigo O Mascarenhas ${ }^{1}$, Leandro F Prezotto ${ }^{1}$, André Luiz P Perondini ${ }^{1}$, Celso Luiz Marino ${ }^{2}$ and Denise \\ Selivon $^{1}$ \\ ${ }^{1}$ Departamento de Genética e Biologia Evolutiva, Instituto de Biociências, Universidade de São Paulo \\ (USP), São Paulo, SP, Brazil. \\ ${ }^{2}$ Departamento de Genética, Instituto de Biociências, Universidade Estadual Paulista (UNESP), Botucatu, \\ SP, Brazil.
}

\begin{abstract}
The endosymbiont Wolbachia is efficiently transmitted from females to their progenies, but horizontal transmission between different taxa is also known to occur. Aiming to determine if horizontal transmission might have occurred between Anastrepha fruit flies and associated braconid wasps, infection by Wolbachia was screened by amplification of a fragment of the wsp gene. Eight species of the genus Anastrepha were analyzed, from which six species of associated parasitoid wasps were recovered. The endosymbiont was found in seven Anastrepha species and in five species of braconids. The WSP Typing methodology detected eight wsp alleles belonging to Wolbachia supergroup A. Three were already known and five were new ones, among which four were found to be putative recombinant haplotypes. Two samples of Anastrepha obliqua and one sample of Doryctobracon brasiliensis showed multiple infection. Single infection by Wolbachia was found in the majority of samples. The distribution of Wolbachia harboring distinct alleles differed significantly between fruit flies and wasps. However, in nine samples of fruit flies and associated wasps, Wolbachia harbored the same wsp allele. These congruences suggest that horizontal transfer of Wolbachia might have occurred in the communities of fruit flies and their braconid parasitoids.
\end{abstract}

Keywords: Bacteria, fruit flies, horizontal transmission, wsp gene, recombination.

Received: March 21, 2016; Accepted: June 10, 2016.

\section{Introduction}

The endosymbiotic bacteria Wolbachia (alphaproteobacteria; Rickettsiales) is an intracellular parasite. It has been associated with the manipulation of its host's reproduction by induction of several phenotypes, such as cytoplasmic incompatibility (CI) in several insect species, parthenogenesis in Hymenoptera, feminization of genetic males, and male killing in Coleoptera, Lepidoptera, Diptera and Pseudoscorpiones (Werren, 1997; Bourtzis and O’Neill, 1998; Bourtzis et al., 2003; Werren et al., 2008). However, the bacteria may be beneficial to their hosts by interfering positively in several fitness components of males and females. In such cases, the relationships between Wolbachia and their hosts evolved from a status of parasitism to mutualistic relationships (Werren et al., 2008; Serbus et al., 2008; Saridaki and Bourtzis, 2010). Previous data have indicated that species infection rates were variable but could account for the infection of 40 to $70 \%$ of ar-

Send correspondence to Denise Selivon. Departamento de Genética e Biologia Evolutiva, Instituto de Biociências, Universidade de São Paulo, Rua do Matão 277, 05088-090 São Paulo, SP, Brazil. E-mail: dselivon@ib.usp.br thropod species (Werren and Windsor, 2000; Jeyaprakash and Hoy, 2000; Hilgenboecker et al., 2008; Zug and Hammerstein, 2012).

Wolbachia are found dispersed in various tissues of the hosts, and their presence in the female germ line assures a highly efficient maternal transmission (Werren, 1997; Dobson et al., 1999). Although the infection is usually pervasive in populations, even if it started with few infected females, it was argued that vertical transmission alone does not explain the large distribution of the bacteria among arthropods. Moreover, phylogenies of Wolbachia are usually incongruent with phylogenies of their hosts. Hence, horizontal transmission was assumed as a possible mechanism promoting the spread of the bacteria among taxa of related organisms, as well as among those showing close relationships, like prey-predator, parasite-host, and parasitoidhosts (O’Neill et al., 1992; Werren et al., 1995, 2008; Vavre et al., 1999; Noda et al., 2001; Dedeine et al., 2005; Baldo et al., 2006a, 2008; Stahlhut et al., 2010; Pattabhiramaiah et al., 2011; Le Clec'h et al., 2013). Other ways of horizontal transmission were found between species of herbivorous insects that acquire Wolbachia strains by in- 
gesting tissues of the host plants contaminated with the bacteria (Kittayapong et al., 2003; Sintupachee et al., 2006; Yang et al., 2013), or by contact of haemolymph through wounds in the host's bodies (Rigaud and Juchault, 1995). Horizontal transmission was also considered the route of infection by multiple Wolbachia strains, as is frequently observed in many species of Coleoptera, Diptera, Hymenoptera and Lepidoptera (Werren et al., 1995; Jamnongluk et al., 2002; Rokas et al., 2002; Reuter and Keller, 2003; Hiroki et al., 2004; Schuler et al., 2011; Yang et al., 2012, 2013; Augustinos et al., 2014).

Experimentally, natural transmission of bacteria was found between a non-infected parasitoid (Leptopilina boulardi) that acquired some Wolbachia strains after culture with its infected host (Drosophila simulans) (Heath et al., 1999). Experimental transmission of Wolbachia from infected hosts to non-infected eggs by microinjection of egg cytoplasm was obtained, for example, between closely related host species, Drosophila simulans and $D$. melanogaster (Boyle et al., 1993), between flies of different genera, Rhagoletis cerasi and Ceratitis capitata (Zabalou et al., 2004), and between species of different families, like Drosophila simulans and Aedes albopictus (Braig et al., 1994).

The large variability of Wolbachia strains, either in single or multiple infection cases, may also be due to the appearance of distinct haplotypes by recombination events. Putative recombinant haplotypes involving distinct Wolbachia strains were found to be widespread among insect species (Jiggins et al., 2001; Werren and Bartos, 2001; Reuter and Keller, 2003; Baldo et al., 2005, 2006a; Arthofer et al., 2009; Yang et al., 2012, 2013). Intragenic recombination occurs frequently in the wsp gene of Wolbachia, infecting a large number of insect species (Baldo et al., 2005, 2006a). This gene is highly variable and, for this reason, not reliable for phylogenetic inferences, but it is useful for identifying groups of closely related alleles (Baldo and Werren, 2007). The high variability is not distributed evenly along the gene: there are four hypervariable regions (HVR) that are isolated from each other by conserved regions (CR) (Baldo et al., 2005). The portions of the Wsp protein coded by the HVRs form loops outside the bacteria cell and are assumed to participate in establishing the relationships of the bacteria with their hosts. Actually, new Wsp proteins are due largely to mutation, but recombination seems to account for $50 \%$ of amino acid differences in recent diverged proteins (Baldo et al., 2010).

Among the frugivorous tephritid flies, Wolbachia was found to infect species of the genera Rhagoletis (Riegler and Stauffer, 2002; Schuler et al., 2009, 2011, 2013; Arthofer et al., 2009; Drosopoulou et al., 2011; Augustinos et al., 2014), Bactrocera (Kittayapong et al., 2000; Jamnongluk et al., 2002; Liu et al., 2006; Sun et al., 2007; Morrow et al., 2014, 2015), Dacus (Kittayapong et al., 2000), Ceratitis (Rocha et al., 2005), and Anastrepha (Werren et al., 1995; Selivon et al., 2002; Coscrato, et al., 2009; Cáceres et al., 2009; Marcon et al., 2011; Martínez et al., 2012). Like in other cases of Wolbachia infections, a non-congruence of the endosymbiont phylogenies and their hosts was also observed in fruit flies, suggesting the occurrence of horizontal transmission events (Jamnongluk et al., 2002; Sun et al., 2007; Coscrato et al., 2009). Another way of horizontal transfer of the bacteria among fruit flies would be through the common association of fruit flies with parasitoids, as suggested for species of Bactrocera and parasitoid wasps of the genus Fopius (Morrow et al., 2014).

Parasitoid wasps of the families Braconidae, Figitidae (Eucolinae) and Pteromalidae have a worldwide distribution (O’Neill et al., 1992; Godfray, 1994), and in the Brazilian territory they are largely dispersed, using as hosts several insect species including Anastrepha (Canal and Zucchi, 2000). Although the Braconidae encompass the largest number of species that use fruit flies as hosts (Leonel Jr et al., 1995; Ovruski et al., 2000; Marinho et al., 2009), no studies about Wolbachia infection in these fruit fly-parasitoid communities were found. The present report describes the results of an analysis of Wolbachia infection involving communities of eight species of Anastrepha and six species of braconid wasps derived from these fly hosts. The data show: (a) a very large species infection rate in both insect groups, (b) that several species of wasps share identical Wolbachia wsp alleles with distinct species of their Anastrepha hosts, and (c) signatures of recombination between wsp alleles. The data indicate that horizontal transmission of the wsp gene may have occurred in guilds of fruit fly-parasitoids.

\section{Materials and Methods}

\section{Collection of infested fruits}

The species of fruit flies and the associated braconid parasitoids used in the present study derived from infested fruits collected in several locations in Brazil (Table 1 and Figure S1). The localities of collection were chosen in order to collect fruits known, in most cases, to host single species of Anastrepha. For example, after several collections only Anastrepha obliqua was recovered from starfruit from the city of Indaiatuba. The fruits brought to the laboratory were divided into small groups, which were kept under standard conditions until emergence of adult flies. The emerged adult females of both fruit flies and parasitoids were fixed in $100 \%$ ethanol and stored at $-20{ }^{\circ} \mathrm{C}$. Identification of fruit flies and braconid wasp species was made according to established criteria (Canal and Zucchi, 2000; Zucchi, 2007; Selivon et al., 2004, 2005).

\section{DNA extraction and amplification}

DNA was extracted from abdomens of females (Jowett, 1986). For the fruit flies, abdomens from three to 
Table 1 - Collection sites host fruits and recovered species of Anastrepha and of associated braconid wasps.

\begin{tabular}{|c|c|c|c|}
\hline Collection sites & Host fruits & Anastrepha & wasps \\
\hline São Paulo-SP & "pombeiro" & amita & D. areolatus \\
\hline \multirow[t]{3}{*}{$23^{\circ} 32^{\prime} \mathrm{S} / 46^{\circ} 37^{\prime} \mathrm{W}$} & Citharexylum myriantum & & D. brasiliensis \\
\hline & & & O. bellus \\
\hline & & & U. anastrephae \\
\hline São Paulo-SP & Guava & fraterculus $\mathrm{sp} .1$ & D. areolatus \\
\hline \multirow[t]{3}{*}{$23^{\circ} 32^{\prime} \mathrm{S} / 46^{\circ} 37^{\prime} \mathrm{W}$} & Psidium guajava & & D. brasiliensis \\
\hline & & & O. bellus \\
\hline & & & U. anastrephae \\
\hline Vargem Grande-SP & Japanese plum & fraterculus $\mathrm{sp} .1$ & D. brasiliensis \\
\hline $23^{\circ} 39^{\prime} \mathrm{S} / 46^{\circ} 59^{\prime} \mathrm{W}$ & Eriobotrya japonica & & \\
\hline Indaiatuba-SP & star fruit & obliqua & A. anastrepha \\
\hline \multirow[t]{3}{*}{$23^{\circ} 05^{\prime} \mathrm{S} / 47^{\circ} 13^{\prime} \mathrm{W}$} & Averrhoa carambola & & D. areolatus \\
\hline & & & O. bellus \\
\hline & & & U. anastrephae \\
\hline Boiçucanga-SP & tropical almond & fraterculus sp.2 & D. areolatus \\
\hline \multirow[t]{2}{*}{$23^{\circ} 47^{\prime} \mathrm{S} / 45^{\circ} 37^{\prime} \mathrm{W}$} & Terminalia catappa & & O. bellus \\
\hline & & & U. anastrephae \\
\hline Caçapava-SP & star fruit & obliqua & A. anastrephae \\
\hline $22^{\circ} 57^{\prime} \mathrm{S} / 48^{\circ} 11^{\prime} \mathrm{W}$ & Averrhoa carambola & & \\
\hline Taubate-SP & manihot & montei & D. fluminensis \\
\hline $22^{\circ} 57^{\prime} \mathrm{S} / 45^{\circ} 38^{\prime} \mathrm{W}$ & Manihot esculenta & pickeli & D. fluminensis \\
\hline Lorena-SP & mango & obliqua & U. anastrephae \\
\hline $22^{\circ} 44^{\prime} \mathrm{S} / 45^{\circ} 06^{\prime} \mathrm{W}$ & Mangifera indica & & \\
\hline Bemposta-RJ & mango & obliqua & D. areolatus \\
\hline $22^{\circ} 07^{\prime} \mathrm{S} / 43^{\circ} 05^{\prime} \mathrm{W}$ & Mangifera indica & & U. anastrephae \\
\hline Brasília-DF & star fruit & obliqua & D. areolatus \\
\hline \multirow[t]{2}{*}{$15^{\circ} 47^{\prime} \mathrm{S} / 47^{\circ} 55^{\prime} \mathrm{W}$} & Averrhoa carambola & & O. bellus \\
\hline & & & U. anastrephae \\
\hline Natal-RN & "burra leiteira" & macrura & D. areolatus \\
\hline $05^{\circ} 48^{\prime} \mathrm{S} / 35^{\circ} 13^{\prime} \mathrm{W}$ & Ficus organensis & serpentina & D. areolatus \\
\hline
\end{tabular}

seven flies were individually analyzed per species and sample. For the braconids, three to four abdomens were pooled for each extraction, and three to nine extractions were made for samples of each species. Amplification was done using primers for the Wolbachia wsp gene (Zhou et al., 1998), wsp 81F (5TGGTCCAATAGTGATGAAGAAAC3) and wsp 691R (5AAAAATTAAACGCTACTCCA3). The PCR reaction consisted of a $3 \mu \mathrm{L}$ of the extracted DNA of each sample, $2 \mu \mathrm{L}$ of 10 buffer (Invitrogen), $1.0 \mu \mathrm{L}$ of $\mathrm{MgCl}_{2}(50 \mathrm{mM}), 1.0 \mu \mathrm{L}$ of nucleotide mix (5 mM each), 0.5 $\mu \mathrm{L}$ of forward and reverse primers (20 $\mu \mathrm{M}$ each), $1 \mathrm{U}$ of Taq DNA polymerase (Invitrogen), and distilled deionized water to a final volume of $20 \mu \mathrm{L}$. The amplification cycle was as follows: one cycle $\left(2 \mathrm{~min}\right.$ at $\left.95^{\circ} \mathrm{C}\right), 35$ cycles $(1 \mathrm{~min}$ at $95^{\circ} \mathrm{C}, 1 \mathrm{~min}$ at $55^{\circ} \mathrm{C}$, two $2 \mathrm{~min}$ at $75^{\circ} \mathrm{C}$ ), and an extension of $5 \mathrm{~min}$ at $72^{\circ} \mathrm{C}$ (Werren et al., 1995). For electro- phoresis, $5 \mu \mathrm{L}$ of each PCR product were run on a $0.8 \%$ gel to determine the presence and size of the amplified DNA fragments. About $15 \%$ of the PCR products were electrophoresed in $0.8 \%$ agarose gel (Gibco) in horizontal system and TAE $1 \mathrm{X}$ buffer (40 mM Tris-acetate; $1 \mathrm{mM}$ EDTA, $\mathrm{pH}$ $8.0)$ at $86 \mathrm{~V}$. The samples were mixed with $0.015 \%$ bromophenol blue, $0.015 \%$ of xylene cyanol and $30 \%$ of glycerol (20\% in buffer). The DNA fragments were visualized after staining with $5 \mu \mathrm{g} / \mathrm{mL}$ ethidium bromide in a UV transilluminator. Samples of Wolbachia-infected Ceratitis capitata (Rocha et al., 2005) were used as a positive control for the PCR assays. In case of a negative amplification, the sample DNA was tested for amplification of the 28S rDNA using the universal arthropod primers, and samples that were negative were discarded only after changing the DNA concentrations and PCR conditions (Werren et al., 1995). In case of negative results, new DNA extractions from indi- 
viduals of that sample were made and the procedure repeated as described above.

\section{Sequencing and cloning}

Fragments of the expected size ( $\sim 650 \mathrm{bp})$ were excised from the agarose gels using a purification kit (MagSep Tissue gDNA, Eppendorf) according to the manufacturer's instructions, and these were then sequenced using the BigDye reaction kit (Applied Biosystems) in an ABI-377 Prism automatic sequencer (Applied Biosystems). Sequence reactions were repeated until at least two replicates of the extremities of each sequence were obtained. The electropherograms were examined by the web tool Electropherogram Quality Analysis (Togawa and Brigido, 2003). Beside these analyses, sequences without signals of PCR artifacts were considered free of errors if they were found in more than two individuals in a given sample, and for unique sequences if their amino acid conceptual translation was achieved without interruptions (Yang et al., 2012). For sequences with evidence of two distinct nucleotides in any given peak in the electropherogram, the amplified fragments were cloned in Top $10 \mathrm{E}$. coli bacteria using the Topo Cloning kit (Invitrogen). Bacteria were grown in $3 \mathrm{~mL}$ of LB culture medium containing $100 \mu \mathrm{g} / \mathrm{mL}$ of Carbemicillin, and incubated overnight at 37 ${ }^{\circ} \mathrm{C}$ under rotation at $200 \mathrm{rpm}$. From the cultures, $1.5 \mathrm{~mL}$ was transferred to a polypropylene tube, and centrifuged at $20,800 \mathrm{~g}$ for $1 \mathrm{~min}$ at room temperature. The pellet was suspended in $100 \mathrm{~mL}$ of GTE ( $20 \mathrm{mM}$ Tris, $50 \mathrm{mM}$ glucose, 10 mM EDTA, pH 8.0) to which $200 \mu \mathrm{L}$ of $0.2 \mathrm{~N} \mathrm{NaOH}, 1 \%$ SDS was added and homogenized by inversion. After addition of $150 \mu \mathrm{L}$ of $3 \mathrm{M}$ sodium acetate $(\mathrm{pH} 4.8$ ), centrifugation at 20,800 g for $6 \mathrm{~min}$, the upper layer was transferred to another tube, pure ethanol was added to a 1.5 $\mathrm{mL}$ final volume and the tube shacken vigorously. After centrifugation, the pellet was washed with $70 \%$ ethanol, dried at $37{ }^{\circ} \mathrm{C}$, and suspended in $50 \mu \mathrm{L}$ of TE buffer containing $20 \mu \mathrm{g} / \mathrm{mL}$ of RNase A (Sigma). Ten clones of each sample were sequenced using the primers included in the cloning kit. The sequences are available at the Wolbachia WSP database and may be assessed by their allele codes.

\section{Sequence analysis}

The sequences were aligned using the Clustal Omega program (Sievers et al., 2011). Identification of haplotypes was made by the DnaSP 5.10 software (Librado and Rozas, 2009), and the distance matrices between sequences of the wsp gene were generated in MEGA 6 software (Tamura et al., 2013). The sequences were submitted to the WSP Typing methodology to determine the existing WSP alleles. This is based on the independent variability of the four hypervariable regions and half of each conserved region $(\mathrm{HVR}+)$. The alleles are defined by four numerical codes and each identifies one of the HVR+ regions (Baldo et al., 2005). The HVR profiles were compared to se- quences in the Wolbachia WSP database and those that had no matches were submitted to the Wolbachia database curators for inclusion as new alleles. Occurrence of $w s p$ alleles in Wolbachia found in fruit flies and in wasp species was assessed by a chi-square test in a contingency table. Alleles found in low frequency $(\mathrm{n}<2)$ could not be included in these tests (Stahlhut et al., 2010). Search for signatures of recombination was made by comparison among the HVR amino acid motifs (Baldo et al., 2005) and by three statistical methods: Maxchi (Maynard Smith, 1992), Geneconv (Posada and Crandall, 2001) and Chimaera (Padidam et al., 1999), implemented in the RDP3.10 software (Heath et al., 2006). In these tests, parameters previously used in analyses of other insects were employed (Baldo et al., 2006b).

\section{Results and Discussion}

\section{Recovered species of fruit flies and wasps}

From the 11 samples of infested fruits, eight species of Anastrepha were recovered: A. amita, A. macrura, A. montei, A. obliqua, A. pickeli, A. serpentina, A. sp.1 aff. fraterculus and $A$. sp.2 aff. fraterculus (Table 1). Among the braconid wasps, six species were recovered: Doryctobracon areolatus, Doryctobracon brasiliensis, Doryctobracon fluminensis, Opius bellus, Utetes anastrephae, and Asobara anastrephae (Table 1). Table 1 also shows the associations of the six wasp species with their Anastrepha hosts. The species of braconid wasps that were recovered confirm previous observations that they are commonly dispersed in southeastern Brazil (Canal and Zucchi, 2000; Marinho et al., 2009). An Anastrepha species not usually found in southern regions (Anastrepha macrura) was collected in a sample from the northeastern city of Natal (Zucchi, 2007).

\section{Detection and characterization of Wolbachia wsp alleles}

Out of 62 females of eight species of Anastrepha individually screened for Wolbachia, 58 turned out to be infected. The sample of $A$. serpentina was the only uninfected one. One hundred and twenty-four out of 140 samples of the six species of braconid wasps, each composed of pooled individuals, were positive for Wolbachia, while two samples of Asobara anastrephae and one sample of $O$. bellus were not infected. However, a sample of $A$. serpentina from southeastern Brazil was previously found to host a strain of Wolbachia (Coscrato et al., 2009). The only other case of Wolbachia-free Anastrepha was found in samples of $A$. ludens from Mexico (Martínez et al., 2012). From the Anastrepha species screened so far, 14 out of 15 (93.3\%) were infected by Wolbachia (Werren et al., 1995; Selivon et al., 2002; Coscrato et al., 2009; Cáceres et al., 2009; Martínez et al., 2012). This is a very high infection rate even among tephritid flies since, for example, in Bactrocera from Thailand Wolbachia infection occurred in 
$28.3 \%$ of the species (Kittayapong et al., 2000) and in 37\% of species of fruit flies, including Bactrocera from Australia (Morrow et al., 2015). Amongst the braconids, five out of six $(83.3 \%)$ species were infected by the endosymbiont, a rate similar to the $84 \%$ (14 out of 17 species) found in fig wasps from China (Yang et al., 2012). Thus, the species infection rate found in Anastrepha and in the parasitoid wasps are among the highest found in insect species which span from 40 to $76 \%$ (Werren and Windsor, 2000; Jeyaprakash and Hoy, 2000; Hilgenboecker et al., 2008; Zug and Hammerstein, 2012).

In every species and samples of fruit flies and wasps, local alignment (BLASTN) of the sequences to the WSP database showed that the amplified fragments were from the wsp gene of supergroup A Wolbachia. Species of the Bactrocera and Rhagoletis fruit flies harbor Wolbachia strains of groups A and B (Jamnongluk et al., 2002; Sun et al., 2007; Arthofer et al., 2011), but in Anastrepha, group B was so far found only in A. striata from Mexico (Martínez et al., 2012), and in a sample of unknown origin of nominal A. fraterculus (Cáceres et al., 2009). In line with previous data, infection by Wolbachia supergroup A is prevalent among distinct host insects, including the Diptera and Hymenoptera (Werren et al., 1995; Stahlhut et al., 2010; Baldo et al., 2010).

Among the entire set of nucleotide sequences, regardless of whether they were from the fruit flies or the braconids, DnaSP detected 22 wsp nucleotide haplotypes. Assuming that the distinctiveness of Wolbachia haplotypes is recognized just for those differing in more than $1.5 \%$ (Zhou et al., 1998; Zabalou et al., 2004; Sintupachee et al., 2006), the 22 haplotypes formed eight groups, named as w1, w2, w3, w4, w5, w6, w7 and w8. The intragroup distance varied from 0.002 (w8) to 0.007 (w1), and the intergroup distances varied from $0.022(\mathrm{w} 4 / \mathrm{w} 7)$ to 0.258 (w1/w7) (Table S1). The sequences were further analyzed by the WSP Typing methodology (Baldo et al., 2005) that, based on the four HVR peptides, detected eight $w s p$ alleles of Wolbachia infecting the guilds of fruit flies and braconid wasps (Table 2). These wsp alleles correspond to the eight haplotypes determined by the nucleotide sequences: wsp75 (w8), wsp-23 (w3), wsp-156 (w1), wsp-680 (w2), wsp681(w4), wsp-682 (w5), wsp-683 (w6) and wsp-684 (w7). Three WSP alleles, wsp-23, wsp-75 and wsp-156, were found in the WSP database and occur in Wolbachia infecting a variety of insect species (Baldo et al., 2005, 2010). The other five alleles, wsp-680, wsp-681, wsp-682, wsp683 and wsp-684, are novel wsp alleles detected in the present analysis.

The present data show that the number of different wsp alleles of Wolbachia infecting Anastrepha species is higher than found in a previous screening based on nucleotide haplotypes of 10 species, in which the sequences were very similar to wMel (Coscrato et al., 2009). The high rate of species infection can be explained by assuming that the
Table 2 - Wsp HVR profiles of Wolbachia infecting Anastrepha and parasitoid braconid wasps.

\begin{tabular}{lccccc}
\hline \multirow{2}{*}{$\begin{array}{l}\text { Haplotype } \\
\text { groups }\end{array}$} & \multicolumn{4}{c}{ Peptide codes } & \multirow{2}{*}{$\begin{array}{l}\text { WSP } \\
\text { alleles }\end{array}$} \\
\cline { 2 - 4 } & HVR1+ & HVR2+ & HVR3+ & HVR4+ & \\
\hline w1.0 & 71 & 34 & 15 & 25 & 156 \\
w2.0 & 235 & 15 & 17 & 14 & 680 \\
w3.0 & 1 & 12 & 21 & 19 & 23 \\
w4.0 & 1 & 12 & 265 & 14 & 681 \\
w5.0 & 236 & 12 & 21 & 19 & 682 \\
w6.0 & 1 & 15 & 17 & 14 & 683 \\
w7.0 & 232 & 12 & 266 & 14 & 684 \\
w8.0 & 11 & 9 & 15 & 25 & 75 \\
\hline
\end{tabular}

fruit flies and parasitoid wasps may be highly prone to infection by the bacteria, and may be favored by the combination of their habitats and life strategies, allowing horizontal transmissions, in line with observations in other insect species (Werren et al., 2008; Stahlhut et al., 2010). These facts may also be a possible explanation for infection by multiple Wolbachia strains found in many hosts insects (Werren et al., 1995; Rokas et al., 2002; Kittayapong et al., 2003; Reuter and Keller, 2003; Hiroki et al., 2004; Yang et al., 2013).

\section{Wsp alleles in fruit flies and parasitoid wasps}

Table 3 summarizes the Wolbachia harboring distinct $w s p$ alleles found in each species and sample of Anastrepha, as well as in the braconids that emerged from the puparia of the sampled host fruit flies. The present analysis showed that most Anastrepha species were infected by a single Wolbachia strain, but a double infection (sample from Indaiatuba) and a multiple infection (sample from Caçapava) were found in A. obliqua. Similarly, two Wolbachia bearing distinct alleles were found only in a sample (from São Paulo) of the parasitoid D. brasiliensis, while a single infection was found in the other five wasp species. The data in Table 4 show significant differences $\left(\mathrm{X}^{2}=33.13\right.$, d.f. $\left.=2, \mathrm{P}<0.001\right)$ in the distribution of Wolbachia harboring distinct $w s p$ alleles between the fruit flies and the wasps. Wolbachia wsp-23 was more frequent in flies $(76.3 \%)$ than in wasps, while Wolbachia wsp-156 and Wolbachia wsp-680 were more frequent in wasps than in the fruit flies hosts $(80.9 \%$ and $94.1 \%$, respectively). In the majority of cases, Wolbachia infecting the fruit flies were distinct from those detected in the braconid wasps with respect to the $w s p$ alleles. However, in some samples, Wolbachia infecting the fruit flies had an identical wsp allele as the bacteria infecting the parasitoid wasps. Table 5 shows the congruence involving Wolbachia bearing allele wsp-23 or allele wsp-156 between fruit flies and wasps. The striking cases seem to be those of Wolbachia wsp-156 found in $D$. fluminensis derived from two species of fruit flies, and of Wolbachia wsp-23 that was found in Utetes 
Table 3 - Wolbachia alleles* in species of Anastrepha associated with braconid parasitoids, localities of collection and number of samples (N) screened for Wolbachia.

\begin{tabular}{|c|c|c|c|c|c|c|}
\hline \multirow{2}{*}{$\begin{array}{l}\text { Anastrepha } \\
\text { Species }\end{array}$} & \multirow[b]{2}{*}{ Wolbachia } & \multirow[b]{2}{*}{$\mathrm{N}^{\mathrm{a}}$} & \multicolumn{3}{|l|}{ Braconid wasps } & \multirow[t]{2}{*}{ Samples } \\
\hline & & & Species & Wolbachia & $\mathrm{N}^{\mathrm{b}}$ & \\
\hline \multirow[t]{4}{*}{ amita } & wsp-23 & 5 & D. areolatus & wsp-680 & 6 & São Paulo-SP \\
\hline & & & D. brasiliensis & wsp- $75,-156$ & 6 & \\
\hline & & & O. bellus & not infected & 6 & \\
\hline & & & U. anastrephae & wsp-23 & 5 & \\
\hline fraterculus & wsp-23 & 4 & D. brasiliensis & wsp-156 & 4 & Vargem Grande-SP \\
\hline \multirow[t]{4}{*}{ (sp.1) } & wsp-23 & 7 & D. areolatus & wsp-680 & 6 & São Paulo-SP \\
\hline & & & D. brasiliensis & wsp-156 & 4 & \\
\hline & & & O. bellus & wsp-680 & 6 & \\
\hline & & & U. anastrephae & wsp-23 & 5 & \\
\hline fraterculus & wsp-23 & 6 & D. areolatus & wsp-680 & 6 & Boiçucanga-SP \\
\hline \multirow[t]{2}{*}{$(\mathrm{sp} .2)$} & & & O. bellus & wsp-680 & 5 & \\
\hline & & & U. anastrephae & wsp-23 & 6 & \\
\hline macrura & wsp-156 & 4 & D. areolatus & wsp-156 & 4 & Natal-RN \\
\hline serpentina & not infected & 4 & D. areolatus & wsp-156 & 4 & \\
\hline montei & wsp-156 & 4 & D. fluminensis & wsp-156 & 4 & Taubaté-SP \\
\hline pickeli & wsp-156 & 4 & D. fluminensis & wsp-156 & 4 & \\
\hline \multirow[t]{11}{*}{ obliqua } & wsp-23, -684 & 6 & A. anastrephae & not infected & 4 & Indaiatuba-SP \\
\hline & & & D. areolatus & wsp-156 & 6 & \\
\hline & & & O. bellus & wsp-23 & 6 & \\
\hline & & & U. anastrephae & wsp-23 & 6 & \\
\hline & wsp-23 & 4 & D. areolatus & wsp-156 & 6 & Lorena-SP \\
\hline & wsp-23 & 4 & D. areolatus & wsp-156 & 6 & Bemposta-RJ \\
\hline & & & U. anastrephae & wsp-23 & 6 & \\
\hline & wsp-23 & 4 & D. areolatus & wsp-156 & 5 & Brasília-DF \\
\hline & & & O. bellus & wsp-680 & 3 & \\
\hline & & & U. anastrephae & wsp-23 & 5 & \\
\hline & $\begin{array}{l}\text { wsp- } 23,-680, \\
-681,-682,-683\end{array}$ & 6 & A. anastrephae & not infected & 6 & Caçapava-SP \\
\hline
\end{tabular}

*In bold, congruence of Wolbachia alleles in fruit flies and associated wasps

$\mathrm{N}^{\mathrm{a}}$ : number of Anastrepha females individually screened. $\mathrm{N}^{\mathrm{b}}$ : number of screened samples of wasps each composed of 3-4 pooled females.

Table 4 - Distribution of Wolbachia bearing distinct alleles in the fruit flies and wasps.

\begin{tabular}{|c|c|c|c|c|c|c|}
\hline \multirow[t]{2}{*}{ Species } & \multicolumn{4}{|c|}{ wsp alleles* } & \multirow[t]{2}{*}{ Test } & \multirow[t]{2}{*}{ P-value } \\
\hline & 23 & 156 & 680 & Total & & \\
\hline $\begin{array}{l}\text { Fruit } \\
\text { flies }\end{array}$ & 45 & 12 & 2 & 59 & $\begin{array}{l}X^{2}= \\
33.13\end{array}$ & $<0.001$ \\
\hline $\begin{array}{l}\text { Braconid } \\
\text { wasps }\end{array}$ & 39 & 51 & 32 & 122 & & \\
\hline Total & 84 & 63 & 34 & 181 & & \\
\hline
\end{tabular}

*Alleles wsp-75 and the recombinants were not included due to insufficient numbers.

anastrephae derived from four species of Anastrepha. These data indicate that horizontal transmission might have occurred in the communities of fruit flies and braconid wasps, similarly to what was assumed in guilds of other insects with their parasitoid wasps (Vavre et al., 1999; Yang et al., 2012; Yang et al., 2013; Morrow et al., 2014).

\section{Recombination between wsp alleles}

The presence of two or more wsp sequences in single individuals offers an opportunity for the appearance of new haplotypes through events of recombination, which consequently contributes to the increase in the number of Wolbachia variants. Recombination between Wolbachia sequences is widespread among insects, and the recombinant haplotypes are assumed to be functional (Reuter and Keller, 2003; Baldo et al., 2005, 2006a,b, 2010; Baldo and Werren, 2007). Those involving the wsp gene seem to produce novel phenotypes that could create new possibilities 
Table 5 - Congruence of Wolbachia infecting species of braconid wasps and their Anastrepha host species.

\begin{tabular}{lccccc}
\hline Braconids & & \multicolumn{3}{c}{ Allelic association flies//braconids } \\
\hline species & samples & $\mathrm{N}$ & $\%$ & alleles & Anastrepha host \\
\hline D. areolatus & 8 & 1 & 0.125 & wsp-156 & macrura \\
D. fluminensis & 2 & 2 & 1.000 & wsp-156 & ontei; pickeli \\
O. bellus & 4 & 1 & 0.250 & wsp-23 & obliqua \\
U. anastrephae & 6 & 6 & 1.000 & wsp-23 & amita; fraterculus-1 fraterculus 2; obliqua \\
\hline
\end{tabular}

for the bacteria to explore new hosts (Werren et al., 2008; Baldo et al., 2010).

In the present study, a search for recombination signatures within the communities of fruit flies-parasitoids was made by analysis of the four HVR amino acid motifs according to Baldo et al. (2005). For these analyses, besides the three alleles previously known, wsp-23, wsp-75 and wsp-156, the WSP database was searched for $w s p$ alleles that would have sequences partially similar to the novel five alleles herein detected. Three Wolbachia alleles with high similarity were found: wsp-31 from Wolbachia infecting Drosophila melanogaster host, and two from ant species hosts, wsp-273 from Formica truncorum and wsp-313 from Formica exsecta hosts. Since wsp-23 is considered an ancestral Wolbachia wsp allele (Baldo et al., 2005, 2010), its amino acid sequence was taken as reference for the present analysis (Figure 1). The previous known alleles, wsp-75 and wsp-156, differed from wsp-23 in their four HVRs (Table 2). As known, wsp-31 from Wolbachia wMel is considered a recombinant sequence differing from wsp-23 in HVR4 (Baldo et al., 2005). The novel wsp-680 has its four HVRs distinct from those of wsp-23. Signals of HVR shuffling were found for the other four new alleles: (a) wsp-681 might be a recombinant allele since it has HVR1 and HVR2 identical to those of wsp-23, but HVR3 and HVR4 identical to the corresponding ones in wsp-680 and wsp-682; (b) wsp-683 and wsp-684 would be recombinants involving distinct HVRs between wsp-23 and wsp-680. The alleles wsp-75 and wsp-156 seem to be involved in recombination with alleles wsp-273 and wsp-313, both from ant species.

Moreover, signatures of recombination were tested by three statistical methods, Maxchi, Geneconv and Chimaera, and only the putative events concomitantly disclosed by the three methods were considered. Figure 2 shows the results of this analysis and the three methods gave very significant $P$ values $(P<0.000001)$ for every case tested. The data confirmed the visual analysis made on the HVR amino acid motifs described above, and showed that wsp-681 (Figure 2A) and wsp-684 (Figure 2B) may represent distinct recombinant haplotypes between wsp-23 and wsp-680. Two other cases were found involving four sequences with a single breakpoint each. As shown in Figure $2 \mathrm{C}$, besides the parental sequences (wsp- 23 and wsp680 ), two putative recombinant sequences were found (wsp-682 and wsp-683), and, shown in Figure 2D, two parental sequences (wsp-156 and wsp-313) and two possible reciprocal recombinants (wsp-75 and wsp-273) were found. The origin of these reciprocal recombinant sequences could be due to independent events of recombination or to reciprocal exchange of single events, as discussed previously for putative recombination in other insects (Baldo et al., 2005). In every case of recombination the breakpoints occurred in the limits of the HVRs and the CRs intervening regions, as was usually described for wsp recombination in other insects (Baldo et al., 2005).

Signatures of intragenic recombination of the wsp gene, detected for the first time in Anastrepha hosts in the
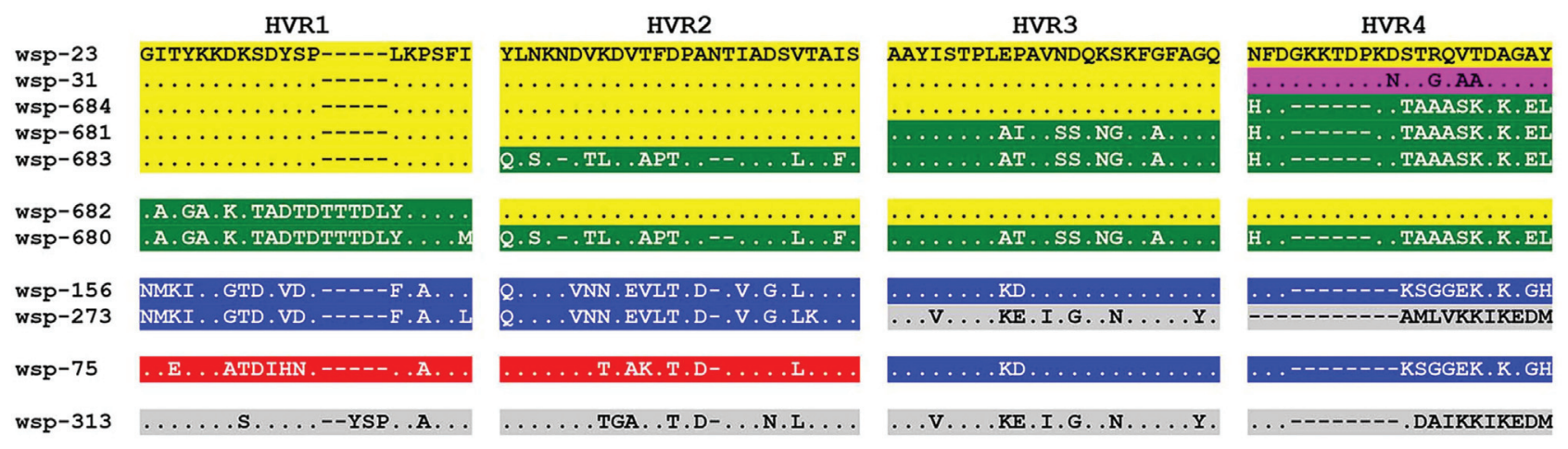

Figure 1 - Amino acid motifs of the hypervariable regions (HVRs) of Wolbachia wsp alleles infecting species of Anastrepha and associated parasitoid braconid wasps. The sequences were aligned relative to the wsp-23 allele. The intervening conserved regions (CR) were omitted from the sequences. The HVR motifs were grouped according to similarity of polymorphism and taking HVR1 as the reference for grouping. Each wsp allele has a unique combination of HVRs indicated by colors, which are interpreted as the result of HVR shuffling. 


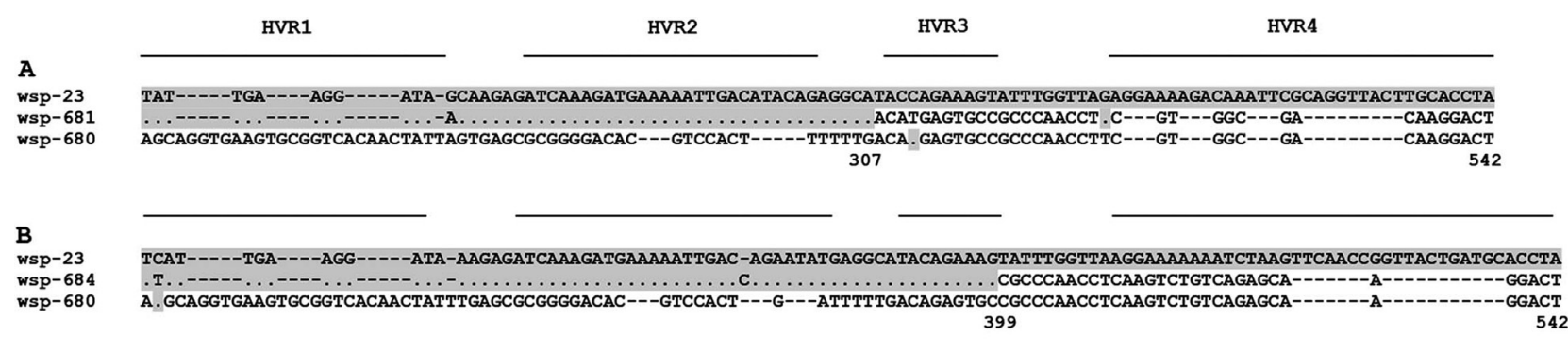

C

wsp-23

wsp-682

wsp-680

TAT-----TGA----AGG-----ATA-AAGAGATCAAAGATGAAAACATTGAC-AGAATATGAGGCAATACAGAAAGTATTTGGTTAAGGAAAAAAATCTAAGTTCAACCGGTTACTGATGCACCTA

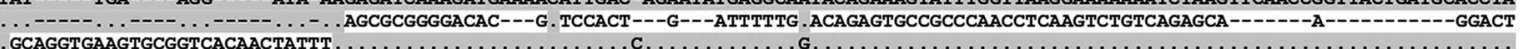

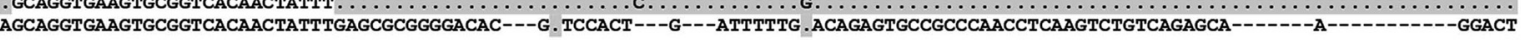
105

D wsp-156

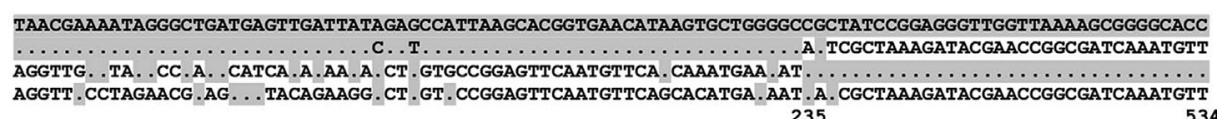

Figure 2 - Putative recombination detected among Wolbachia wsp alleles infecting species of Anastrepha and associated parasitoid braconid wasps. In each alignment, only the polymorphic sites of the sequences are shown. Gray shaded parts of sequences are polymorphisms shared with the top sequence in each alignment. Sequences in the middle of each alignment were indicated as recombinant sequences, and the top and bottom sequences as the two parental sequences. The numbers below the alignments indicate the approximate nucleotide position of the breakpoints detected by three methods (Maxchi, Geneconv, Chimaera). The lines above the sequences indicate the position of the four HVRs.

present analysis, were found in Wolbachia infecting Anastrepha obliqua. The other case of inferred putative recombination involved two alleles, wsp-75 and wsp-156, found in the parasitoid Doryctobracon brasiliensis, with wsp sequences of Wolbachia previously found in two ant species, allele wsp-273, from Formica truncorum host, and wsp-313 from $F$. exsecta host. The way these putative recombinant events have occurred is unknown, but it should involve the presence of different Wolbachia strains in the fruit flies and/or wasps and in the ant species. Evidence of interspecies transfer of Wolbachia was found previously in the social parasitism of two ant species (Solenopsis spp) with parasitoids and a social parasite (Dedeine et al., 2005). In this scenario, besides the close ecological relationships between fruit flies and parasitoid wasps, one may assume that they also share ecological proximity to ants. Indeed, fruit fly species have ants as one of their most important predators during the life stages when they are exposed in soil, as mature larvae when they leave the fruits, as pupae and as emerging adults (Bateman, 1992). Hence, predation of Anastrepha by ants infected with Wolbachia and carrying eggs of parasitoid wasps, may be a possible way of horizontal transmission of Wolbachia between these three insect clades, and could account for the suggestive recombination events herein described.

Recombination between Wolbachia haplotypes seems infrequent among fruit fly hosts. Strain wCer3 of Rhagoletis has been suggested to be a recombinant between A and B Wolbachia supergroups (Arthofer et al., 2009), and no recombinants were yet described in the genus Bactrocera (Kittayapong et al., 2000; Jamnongluk et al., 2002; Sun et al., 2007; Morrow et al., 2014, 2015). Our data indicate that a similar situation seems to occur for Wolbachia infecting Anastrepha species.

\section{Concluding Remarks}

The present analysis shows a high infection rate for fruit flies and braconid wasps and the occurrence of putative intragenic recombination between Wolbachia wsp sequences. By screening for Wolbachia infection in Anastrepha species and in braconid wasps that emerged from samples of these fly species we obtained for the first time strong evidence for horizontal transmission between these two groups of insects. Horizontal transmission also explains the widespread occurrence of Wolbachia bearing a given $w s p$ allele, as is known for a large number of insect species (Baldo et al., 2010; Stahlhut et al., 2010). One such case is the ancestral allele wsp-23 detected in Wolbachia from at least 21 species, 11 genera and 11 families, but found preferentially in Diptera and Hymenoptera (Baldo et al., 2010). Wolbachia bearing this allele was found also in tephritid flies, in species of Anastrepha (Coscrato et al., 2009), Rhagoletis cerasi (wCer2) (Arthofer et al., 2011), $R$. pomonella (wPom1) (Schuler et al., 2011), and in the flywasp guilds, studied herein. Since Wolbachia strains usually do not persist for long periods of time in a given host (Baldo et al., 2008, 2010), the most parsimonious hypothesis to explain the presence of Wolbachia wsp-23 in Rhagoletis, in Anastrepha and in the parasitoids found, might be by horizontal transmission. 


\section{Acknowledgments}

The present study was supported by a grant from Fundação de Amparo à Pesquisa do Estado de São Paulo, Brazil (Proc. 2010/52040-8) to DS. LFP had a doctoral scholarship from CAPES and DS had a fellowship from CNPq.

\section{References}

Arthofer W, Riegler M, Schneider D, Krammer M, Miller WJ and Stauffer C (2009) Hidden Wolbachia diversity in field populations of the European cherry fruit fly, Rhagoletis cerasi (Diptera, Tephritidae). Mol Ecol 18:3816-3830.

Arthofer W, Riegler M, Schuler H, Schneider D, Moder K, Miller WJ and Stauffer C (2011) Allele intersection analysis: A novel tool for multi locus sequence assignment in multiply infected hosts. PLoS One 6:e22198.

Augustinos AA, Asimakopoulou AK, Moraiti CA, MavraganiTsipidou P, Papadopoulos NT and Bourtzis K (2014) Microsatellite and Wolbachia analysis in Rhagoletis cerasi natural populations: Population structuring and multiple infections. Ecol Evol 4:1943-1962.

Baldo L and Werren JH (2007) Revisiting Wolbachia supergroup typing based on WSP: Spurious lineages and discordance with MLST. Curr Microbiol 55:81-87.

Baldo L, Lo N and Werren JH (2005) Mosaic nature of the Wolbachia surface protein. J Bacteriol 187:5406-5418.

Baldo L, Borderstein S, Wernegreen JJ and Werren JH (2006a) Widespread recombination throughout Wolbachia genomes. Mol Biol Evol 23:437-449.

Baldo L, Dunning Hotopp JC, Jolley KA, Borderstein SR, Biber SA, Choudhury RR, Hayashi C, Maiden MCJ, Tettelin H and Werren J (2006b) Multilocus sequence typing system for the endosymbiont Wolbachia pipientis. Appl Environ Microbiol 72:7098-7110.

Baldo L, Ayoub NA, Hayashi CY, Russell JA, Stahlhut JK and Werren JH (2008) Insight into the routes of Wolbachia invasion: High levels of horizontal transmission in the spider genus Agelenopsis revealed by Wolbachia strain and mitochondrial DNA diversity. Mol Ecol 17:557-569.

Baldo L, Desjardins CA, Russell JA, Stahlhut JK and Werren JH (2010) Accelerated microevolution in an outer membrane protein (OMP) of the intracellular bacteria Wolbachia. BMC Evol Biol 10:e48.

Bateman MA (1992) The ecology of fruit flies. Ann Rev Entomol 17:493-518.

Bourtzis K and O’Neill SL (1998) Wolbachia infections and arthropod reproduction. BioSci 48:287-293.

Bourtzis K, Braig HR and Karr TL (2003) Cytoplasmic incompatibility. In: Bourtzis K and Miller TA (eds) Insect Symbiosis. CRC Press, Boca Raton, pp 217-246.

Boyle L, O'Neill SL, Robertson HM and Karr TL (1993) Interspecific and intraspecific horizontal transfer of Wolbachia in Drosophila. Science 260:1796-1799.

Braig HR, Guzman H, Tesh RB and O'Neill SL (1994) Replacement of the natural Wolbachia symbiont of Drosophila simulans with a mosquito counterpart. Nature 367:453-455.

Cáceres C, Segura DF, Vera MT, Wornoayporn V, Cladera JL, Teal P, Sapountzis P, Bourtzis K, Zacharopoulou A and Robinson AS (2009) Incipient speciation revealed in
Anastrepha fraterculus (Diptera: Tephritidae) by studies on mating compatibility, sex pheromones, hybridization, and cytology. Biol J Linn Soc 97:152-165.

Canal NA and Zucchi RA (2000) Parasitóides - Braconidae. In: Malavasi A and Zucchi RA (eds) Moscas-das-Frutas de Importancia Econômica no Brasil: Conhecimento Básico e Aplicado. Holos Editora, Ribeirão Preto, pp 119-126.

Coscrato VE, Braz ASK, Perondini ALP, Selivon D and Marino CL (2009) Wolbachia in Anastrepha fruit flies (Diptera, Tephritidae). Curr Microbiol 59:295-301.

Dedeine F, Ahrens M, Calcaterra L and Shoemaker DD (2005) Social parasitism in fire ants (Solenopsis spp.): A potential mechanism for interspecies transfer of Wolbachia. Mol Ecol 14:1543-1548.

Dobson SL, Bourtzis K, Braig HR, Jones BF, Zhou W, Rousset F and O'Neill SL (1999) Wolbachia infection are distributed throughout insect somatic and germ line tissues. Insect Biochem Mol Biol 29:153-160.

Drosopoulou E, Augustinos AA, Nakou I, Koepler K, Kounatidis I, Vogt H, Papadopoulos NT, Bourtzis K and MavraganiTsipidou P (2011) Genetic and cytogenetic analysis of the American cherry fruit fly, Rhagoletis cingulata (Diptera; Tephritidae). Genetica 139:1449-1464.

Godfray HCJ (1994) Parasitoids. Behavioral and Evolutionary Ecology. Princeton University Press, Princeton, 488 p.

Heath DB, Butcher RDJ, Whitfield WGF and Hubbard SF (1999) Horizontal transfer of Wolbachia between phylogenetically distant insect species by naturally occurring mechanism. Curr Biol 9:313-316.

Heath L, van der Walt E, Varsani A and Martin DP (2006) Recombination patterns in aphthoviruses mirror those found in other picornaviruses. J Virol 80:11827-11832.

Hilgenboecker H, Hammerstein P, Schlattmann P, Telschow A and Werren JH (2008) How many species are infected with Wolbachia? A statistical analysis of current data. FEMS Microbiol Lett 281:215-220.

Hiroki M, Tagami Y, Miura K and Kato Y (2004) Multiple infection with Wolbachia inducing different reproductive manipulations in the butterfly Eurema hecabe. Proc R Soc Lond B Biol Sci 271:1751-1755.

Jamnongluk W, Kittayapong P, Baimai V and O’Neill SL (2002) Wolbachia infections of tephritid fruit flies: Molecular evidence for five distinct strains in a single host species. Curr Microbiol 45:255-260.

Jeyaprakash A and Hoy MA (2000) Long PCR improves Wolbachia DNA amplification: wsp sequences found in $76 \%$ of sixty-three arthropod species. Insect Mol Biol 9:393-405.

Jiggins FM, von Der Schulenburg JH, Hurst GD and Majerus ME (2001) Recombination confounds interpretations of Wolbachia evolution. Proc R Soc Lond B Biol Sci 268:1423-1427.

Jowett T (1986) Preparation of nucleic acids. In: Roberts DB (ed) Drosophila: A Practical Approach. IRL Press, Oxford, pp 275-286.

Kittayapong P, Milne JR, Tigvattananont S and Baimai V (2000) Distribution of the reproduction-modifying bacteria, Wolbachia, in natural populations of tephritid fruit flies in Thailand. Sci Asia 26:93-103.

Kittayapong P, Jamnongluk W, Thipaksorn A, Milne JR and Sindhusake C (2003) Wolbachia infection complexity 
among insect in the tropical rice-field community. Mol Ecol 12:1049-1060.

Le Clec'h, W, Chevalier FD, Genty L, Bertaux J, Bouchon D and Sicard M (2013) Cannibalism and predation as path for horizontal passage of Wolbachia between terrestrial isopods. PLoS One 8:e60232.

Leonel Jr FL, Zuchi RA and Wharton RA (1995) Distribution and tephritidae hosts (Diptera) of braconid parasitoids (Hymenoptera) in Brazil. Int J Pest Manag 41:199-206.

Librado P and Rozas J (2009) DnaSP v5: A software for comprehensive analysis of DNA polymorphism. Bioinformatics 25:1451-1452.

Liu R, Li ZH, Sun X, Shen ZR and Gao XW (2006) First discovery of Wolbachia infection of Bactrocera (Zeugodacus) tau (Walker) from China. Chinese Bull Entomol 43:368-370.

Marcon HS, Domingues DS, Coscrato VE, Selivon D, Perondini ALP and Marino CL (2011) New mariner elements in Anastrepha species (Diptera, Tephritidae). Neotrop Entomol 40:568-570.

Marinho CF, Souza-Filho MF, Raga A and Zucchi RA (2009) Parasitóides (Hymenoptera: Braconidae) de moscas-dasfrutas (Diptera: Tephritidae) no Estado de São Paulo: Plantas associadas e parasitismo. Neotrop Entomol 38:321-326.

Martínez H, Toledo J, Liedo P and Mateos M (2012) Survey of heritable endosymbionts in southern Mexico populations of the fruit fly species Anastrepha striata and A. ludens. Curr Microbiol 65:711-718.

Maynard Smith J (1992) Analyzing the mosaic structure of genes. J Mol Evol 34:126-129.

Morrow JL, Frommer M, Shearman DCA and Riegler M (2014) Tropical tephritid fruit fly community with high incidence of shared Wolbachia strains as platform for horizontal transmission of endosymbionts. Environ Microbiol 16:36223637.

Morrow JL, Frommer M, Royeer JE, Shearman DCA and Riegler M (2015) Wolbachia pseudogenes and low prevalence infections in tropical but not temperate Australian tephritid fruit flies: Manifestations of lateral gene transfer and endosymbiont spillover? BMC Evol Biol 15:e202.

Noda H, Miyoshi T, Zhang Q, Watanabe K, Deng H and Hoshizaki S (2001) Wolbachia infection shared among planthoppers (Homoptera: Delphacidae) and their endoparasites (Strepsiptera: Elenchidae): A probable case of interspecies transmission. Mol Ecol 10:2101-2106.

O’Neill SL, Giordano R, Colbert AME, Karr TL and Robertson HM (1992) 16S rRNA phylogenetic analysis of the bacterial endosymbionts associated with cytoplasmic incompatibility in insects. Proc Natl Acad Sci U S A 89:2649-2702.

Ovruski SM, Aluja M, Sivinski J and Wharton RA (2000) Hymenopteran parasitoids on fruit-infesting Tephritidae (Diptera) in Latin America and the southern United States: Diversity, distribution, taxonomic status and their use in fruit fly biological control. Integ Pest Manag Rev 5:81-107.

Padidam M, Sawyer S and Fauquet CM (1999) Possible emergence of new geminiviruses by frequent recombination. Virology 265:218-225.

Pattabhiramaiah M, Brückner D and Reddy MS (2011) Horizontal transmission of Wolbachia in the honeybee subspecies Apis melifera carnica and its ectoparasite Varroa destructor. Int J Environ Sci 2:514-523.
Posada D and Crandall KA (2001) Evaluation of methods for detecting recombination from DNA sequences: Computer simulations. Proc Natl Acad Sci U S A 98:13757-13762.

Reuter M and Keller L (2003) High level of multiple Wolbachia infection and recombination in the ant Formica exsecta. Mol Biol Evol 20:749-753.

Riegler M and Stauffer C (2002) Wolbachia infections and superinfections in cytoplasmically incompatible populations of the European cherry fruit fly Rhagoletis cerasi (Diptera, Tethritidae). Mol Ecol 11:2425-2434.

Rigaud T and Juchault P (1995) Success and failure of horizontal transfers of feminizing Wolbachia endosymbionts in woodlice. J Evol Biol 8:249-255.

Rocha LS, Mascarenhas RO, Perondini ALP and Selivon D (2005) Occurrence of Wolbachia in Brazilian samples of Ceratitis capitata (Wiedemann) (Diptera, Tephritidae). Neotrop Entomol 32:527-529.

Rokas A, Atkinson RJ, Nieves-Aldrey JL, West SA and Stone GN (2002) The incidence and diversity of Wolbachia in gallwasps (Hymenoptera; Cynipidae) on oak. Mol Ecol 11:1815-1829.

Saridaki A and Bourtzis K (2010) Wolbachia: More than just a bug in insect genitals. Curr Opin Microbiol 13:67-72.

Schuler H, Arthofer W, Krumböck S, Köppler K, Vogt H, Teixeira LAF, Riegler M and Stauffer C (2009) The bacterial endosymbiont Wolbachia in the invasive cherry fruit fly Rhagoletis cingulata (Diptera, Tephritidae). Mitt Dtsch Ges Allg Angew Entomol 17:99-101.

Schuler H, Arthofer W, Riegler M, Berthau C, Krumböck S, Köppler K, Vogt H, Teixeira LAF and Stauffer C (2011) Multiple Wolbachia infections in Rhagoletis pomonella. Entomol Exp Appl 139:138-144.

Schuler H, Bertheau C, Egan SP, Feder JL, Riegler M, SchlickSteiner BC, Steiner FM, Johannesen J, Kern P, Tuba K, et al. (2013) Evidence of a recent horizontal transmission and spatial spread of Wolbachia from endemic Rhagoletis cerasi (Diptera, Tephhritidae) to invasive Rhagoletis cingulate in Europe. Mol Ecol 22:4101-4111.

Selivon D, Perondini ALP, Ribeiro AF, Marino CL, Lima MMA and Coscrato VE (2002) Wolbachia endosymbionts in a species of the Anastrepha fraterculus complex (Diptera: Tephritidae). Invertebr Reprod Dev 42:121-127.

Selivon D, Vetros C, Fontes L and Perondini ALP (2004) New variant forms in the Anastrepha fraterculus complex (Diptera: Tephritidae). Proceedings of the $6^{\text {th }}$ International Symposium on Fruit Flies of Economic Importance, Isteg Scientific Publ., Irene, pp 253-258.

Selivon D, Perondini ALP and Morgante JS (2005) A geneticmorphological characterization of two cryptic species of the Anastrepha fraterculus complex (Diptera: Tephritidae). Ann Entomol Soc Am 98:367-381.

Serbus LR, Casper-Lindley C, Landmann F and Sullivan W (2008) The genetics and cell biology of Wolbachia-host interactions. Annu Rev Genet 42:683-707.

Sievers F, Wilm A, Dineen DG, Gibson TJ, Karplus K, Li W, Lopez R, McWilliam H, Remmert M, Söding J, et al. (2011) Fast, scalable generation of high-quality protein multiple sequence alignments using Clustal Omega. Mol Syst Biol 7:539.

Sintupachee S, Milne J, Poonchaisri S, Baimai V and Kyttayapong P (2006) Closely related Wolbachia strains within the 
pumpkin arthropod community and the potential for horizontal transmission via the plant. Microbiol Ecol 51:294301.

Stahlhut LK, Desjardins CA, Clark ME, Baldo L, Russell JA, Werren JH and Jaenike J (2010) The mushroom habitat as an ecological arena for global exchange of Wolbachia. Mol Ecol 19:1940-1952.

Sun X, Cul L and Li Z (2007) Diversity and phylogeny of Wolbachia infecting Bactrocera dorsalis (Diptera, Tephritidae) populations from China. Mol Ecol Evol 36:1283-1289.

Tamura K, Stecher G, Peterson D, Filipski A and Kumar S (2013) MEGA6: Molecular Evolutionary Genetics Analysis version 6.0. Mol Biol Evol 30:2725-2729.

Vavre F, Fleury F, Lepetit D, Fouillet P and Boulétreau M (1999) Phylogenetic evidence for horizontal transmission of Wolbachia in host-parasitoid associations. Mol Biol Evol 16:1711-1723

Werren JH (1997) Biology of Wolbachia. Annu Rev Entomol 42:587-609.

Werren JH and Bartos JD (2001) Recombination in Wolbachia. Curr Biol 11:431-435.

Werren JH and Windsor DM (2000) Wolbachia infection frequencies in insects: Evidence of global equilibrium? Proc R Soc Lond B Biol Sci 267:1277-1285.

Werren JH, Zhang W and Guo LR (1995) Evolution and phylogeny of Wolbachia: Reproductive parasites of arthropods. Proc R Soc Lond B Biol Sci 261:55-71.

Werren JH, Baldo L and Clark ME (2008) Wolbachia: Master manipulators of invertebrate biology. Nat Rev Microbiol 6:741-751.

Yang C-Y, Xiao J-H, Niu L-M, Ma G-C, Cook JM, Bian S-N, Fu Y-G and Huang Da-Wei (2012) Chaos of Wolbachia sequences inside the compact fig syconia of Ficus benjamina (Ficus: Moraceae). PLoS One 7:e48882.

Yang X-H, Zhu D-H, Liu Z, Zhao L and Su C-Y (2013) High levels of multiple infections, recombination and horizontal transmission of Wolbachia in the Andricus mukaigawae (Hymenoptera; Cynipidae) communities. PLoS One 8:e78970.
Zabalou S, Riegler M, Theodorakopoulou M, Stauffer C, Savakis C and Bourtzis K (2004) Wolbachia-induced cytoplasmic incompatibility as a means for insect pest population control. Proc Nat Acad Sci U S A 101:15042-15045.

Zhou W, Rousset F and O'Neill S (1998) Phylogeny and PCRbased classification of Wolbachia strains using wsp gene sequences. Proc R Soc Lond B-Biol Sci 265:509-515.

Zucchi RA (2007) Diversidad, distribución y hospedeiros del género Anastrepha in Brasil. In: Hernández-Orttiz V (ed) Moscas de la Fruta en Latinoamérica (Diptera, Tephritidae): Diversidad, Biologia y Manejo. SyG Editores, Mexico City, pp 77-100.

Zug R and Hammerstein P (2012) Still a host of hosts for Wolbachia: Analysis of recent data suggests that $40 \%$ of terrestrial arthropod species are infected. PLoS One 7:e79825843.

\section{Internet Resources}

Wolbachia database, http://www.pubmlst.org/Wolbachia/wsp (January 12, 2016).

Electropherogram Quality Analysis, http:// asparagin.cenargen.embrapa.br/phph/ (August 20, 2015).

Togawa RC and Brigido MM (2003) PHPH: Web based tool for simple electropherogram quality analysis. ${ }^{\text {st }}$ International Conference on Bioinformatics and Computational Biology, Ribeirão Preto, Brazil, http://asparagin.cenargen.embrapa.br/phph/ribeirao_preto_ poster.pdf.

\section{Supplementary Material}

The following online material is available for this article: Figure S1 - Approximate locations where infested fruits were collected in Brazil.

Table S1 - Genetic distances among wsp nucleotide haplotypes of Wolbachia.

Associate Editor: Célia Maria de Almeida Soares

License information: This is an open-access article distributed under the terms of the Creative Commons Attribution License (type CC-BY), which permits unrestricted use, distribution and reproduction in any medium, provided the original article is properly cited. 